\title{
Endoscopic mucosal resection of a mid-esophageal carcinoid with EUS guidance
}

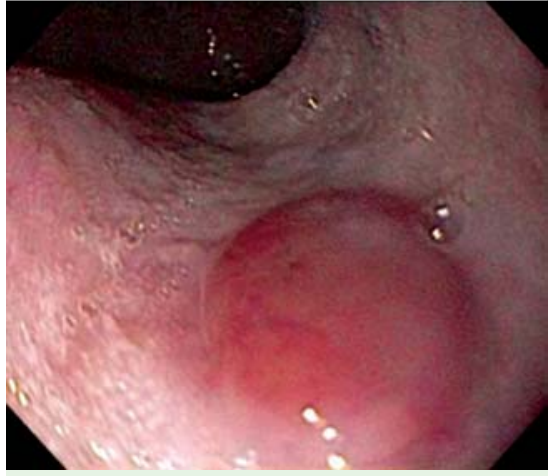

Fig. 1 Endoscopic view of polypoid lesion seen at $28 \mathrm{~cm}$ from the incisors.

A 58-year-old woman with a longstanding history of panhypopituitarism necessitating hydrocortisone and levothyroxine supplementation underwent upper endoscopy because of heartburn, and an esophageal submucosal lesion was detected. Surface biopsies were normal.

Upper endoscopy was repeated at our institution and a $1-\mathrm{cm}$ red-hued submucosal polypoid lesion was noted at $28 \mathrm{~cm}$ from the incisors ( $\bullet$ Fig. 1).

Endoscopic ultrasonography (EUS) was performed with an Olympus 3R 20-MHz ultrasound probe (Olympus, Melville, New York, USA) ( Fig. 2).

The lesion was demarcated in the deep mucosa and submucosa as a homogenous hypoechoic entity without definite muscularis propria invasion. Endoscopic mucosal resection (EMR) was performed utilizing a small submucosal cushion of saline injected by a sclerotherapy needle and a 13-mm snare. The lesion was removed via snare electrocautery. Pathological analysis demonstrated a submucosal neoplasm composed of tumor cells arranged in sheets, glands, and trabeculae without mitoses ( Fig. 3).

Immunohistochemical studies demonstrated positivity for synaptophysin and chromogranin, suggestive of an esophageal carcinoid ( $\bullet$ Figs. 4, $\bullet$ ).

Two weeks after the procedure the patient was contacted and reported no complaints.

Endoscopy 2 months later demonstrated mucosal scarring without residual lesion and surface and "tunnel" biopsies did not reveal any abnormalities. CT imaging of

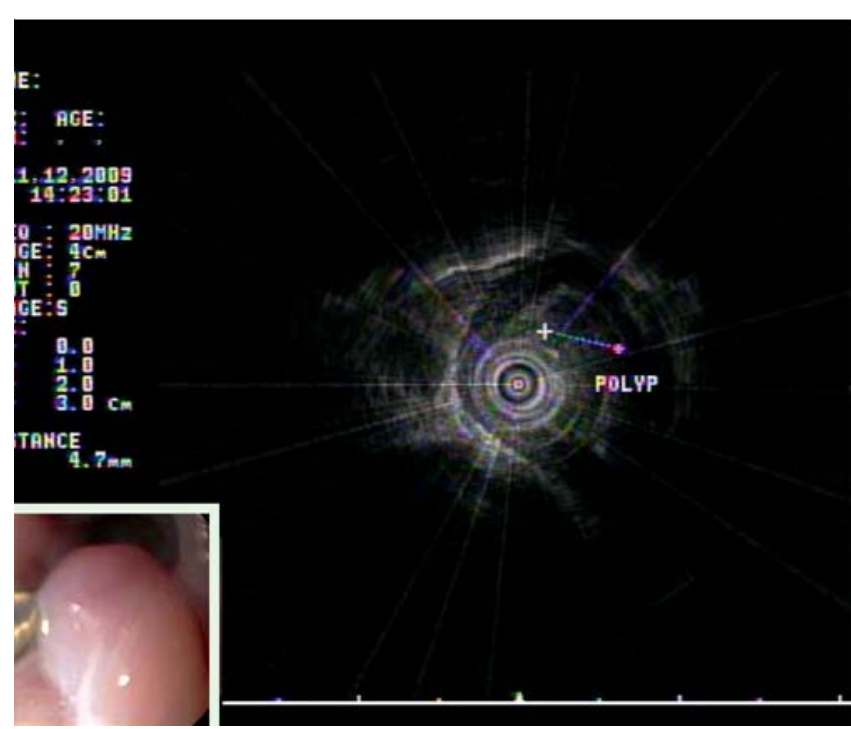

Fig. 2 Endoscopic ultrasound image of the lesion limited to the mucosa.

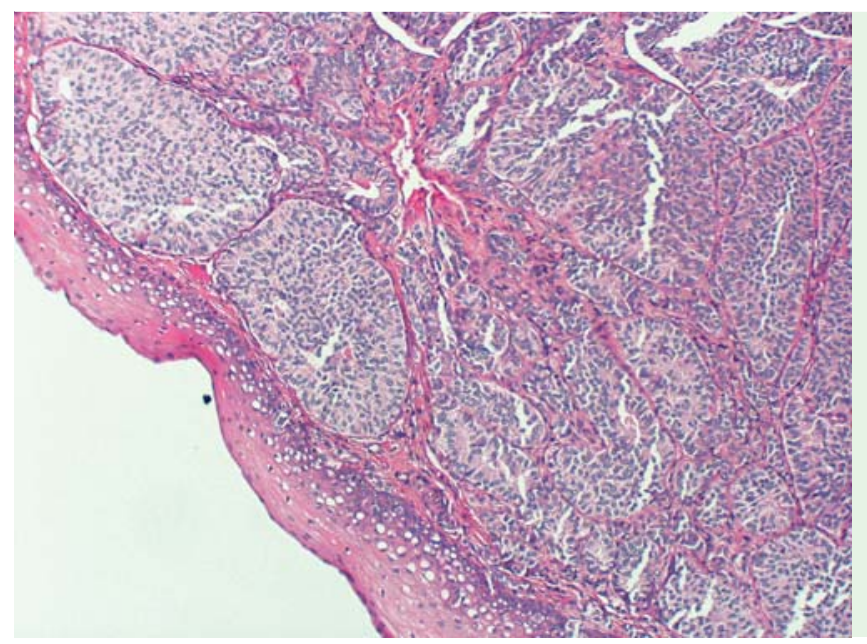

Fig. 3 Submucosal neoplasm composed of tumor cells arranged in sheets, glands, and trabeculae without mitoses.

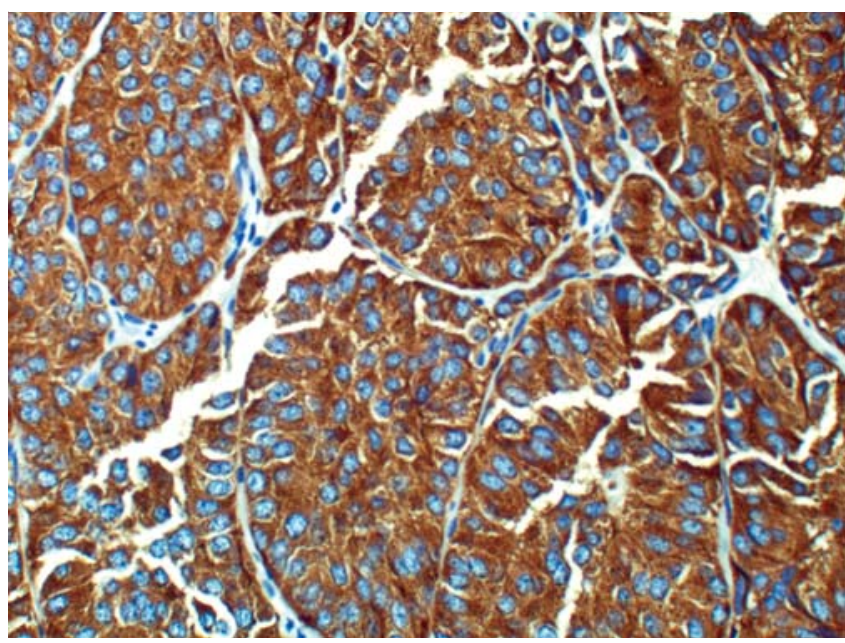

Fig. 4 Synaptophysin immunostain. 


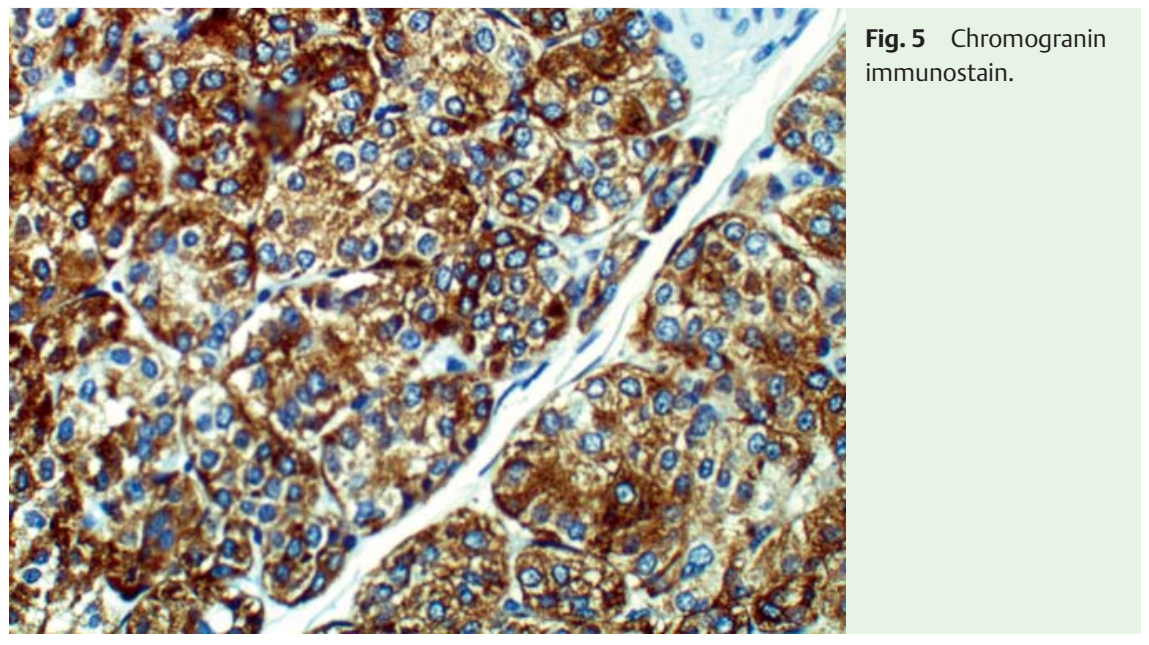

the thorax and octreotide nuclear scan were also within normal limits.

Esophageal carcinoids typically arise from the mucosal lamina propria or the submucosa $[1,2]$. EUS has proven utility in staging and interventional planning (endoscopy or surgery) for gastrointestinal neuroendocrine tumors, and EMR has a solid track record in removal of superficial lesions of the gastrointestinal tract $[3,4]$. Conceivably, use of a ligation band at the lesion base would increase the ease and safety of EMR, and this has been utilized for Barrett's dysplasia and rectal carcinoid resections [5]. Esophageal carcinoid among other esophageal submucosal lesions will be identified because of utiliza- tion of esophagogastroduodenoscopy and perhaps EUS for gastroesophageal reflux disease and other common entities.

Competing interests: None

Endoscopy_UCTN_Code_TTT_1AO_2AG

\section{J. P. Babich', J. Klein², P. Khullar²,}

D. M. Friedel ${ }^{1}$

1 Division of Gastroenterology, Hepatology and Nutrition, Winthrop University Hospital, Mineola, New York, USA

2 Department of Pathology, Winthrop University Hospital, Mineola, New York, USA

\section{References}

1 Lindberg G, Molberg K, Vuitch F, Albores-Saavedra J. Atypical carcinoid of the esophagus. A case report and review of the literature. Cancer 1997; 79: 1476-1481

2 Chuah SK, Hu TH, Kuо CM, Chiu KW et al. Upper gastrointestinal carcinoid tumors incidentally found by endoscopic examinations. World J Gastroenterol 2005; 11: 7028-7032

3 Ahmad NA, Kochman ML, Long WB, Furth EE et al. Efficacy, safety and clinical outcomes of endoscopic mucosal resection: a study of 101 cases. Gastrointest Endosc 2002; 55: 390-396

4 Varas Lorenzo JM, Miquel Collel JM, Maluenda Colomer MD, Boix Valverde J et al. Preoperative detection of gastrointestinal neuroendocrine tumors using endoscopic ultrasonography. Rev Esp Enferm Dig 2006; 98: $828-836$

5 Mashimo Y, Matsuda T, Uraoka T, Suito Y et al. Endoscopic submucosal resection with ligation device is an effective and safe treatment for carcinoid tumors in the lower rectum. J Gastroenterol Hepatol 2008; 23: $218-221$

\section{Bibliography}

DOI 10.1055/s-0030-1255791

Endoscopy 2010; 42: E302 -E303

(c) Georg Thieme Verlag KG Stuttgart . New York . ISSN 0013-726X

\section{Corresponding author}

\section{J. P. Babich, MD}

Division of Gastroenterology,

Hepatology and Nutrition

Winthrop University Hospital

222 Station Plaza North Suite 428

Mineola

New York 11501

USA

Fax: +1-516-663-4655

jpbabich@gmail.com 